\title{
Adsorption-Kinetic Studies of Mordant Exhaust Dyeing of Cotton and Silk Fabrics with Dye Extract of M. Iucida Plant Species
}

\author{
Janani Loum ${ }^{* 1,2}(\mathbb{D})$, Robert Byamukama ${ }^{2}$ and P.A.G. Wanyama ${ }^{3}$ \\ ${ }^{1}$ Department of Polymer, Textile and Industrial Engineering, Busitema University, P.O. Box, 236, Tororo, Uganda \\ ${ }^{2}$ Department of Chemistry, Makerere University, P.O. Box, 7062, Kampala, Uganda \\ ${ }^{3}$ Department of Chemistry, Kyambogo University, P.O. Box 1, Kampala, Uganda
}

Received 18 July 2020 , revised 3 February 2021, accepted 4 February 2021

\begin{abstract}
The kinetics and adsorption isotherms of the extremely slow traditional natural exhaust dyeing that takes many hours or days have been studied purposely to find means of improving the process. The dyeing of cotton and silk fabrics using dye extract of $M$. lucida at $50^{\circ} \mathrm{C}$ were elucidated with graphs to predict the reaction orders and identify the appropriate adsorption isotherm model(s). Since the dye is UV active, changes in UV absorbance were used in place of changes in concentrations. The simultaneous and post mordanting methods followed pseudo-second-order reactions, hence chemisorption. However, mordant application to the dyed fabrics during post mordant followed a pseudo-first-order model, largely physisorption. Dyeing has followed Langmuir and Freundlich isotherm models with linear correlation $\mathbf{r}^{2}$ ranging between 1 and 0.998 . From the Freundlich model and values of Langmuir constant $R_{L}(0.9307$ to 1.0$)$, the process is homogeneous, forming a favourable and linear monolayer. Accordingly, the dyeing speed can be improved by increasing the concentration of dye liquor. Additionally, according to the Freundlich model, higher dye intensity on fabrics is recorded in post mordanting.
\end{abstract}

KEYWORDS

adsorption isotherms, equilibrium, exhaust dyeing, mordant, rate law

\section{Introduction}

The art of dyeing and painting is as old as human existence. Previously, dyes and colourants from natural sources were exclusively used for textile dyeing and printing until the end of the 19th Century. The reversal of this trend was due to the discovery of synthetic dyes that completely replaced dyes from natural sources ${ }^{1}$. The absolute replacement of natural dyes was due to the benefits offered by the synthetic counterpart viz: low cost, ease of use, availability of a wide range of colours and reproducibility of shades. The renewed environmental awareness, increasing demand for eco-safe products, drives forces for the revival of natural dyes for textile colouration ${ }^{2}$ after nearly two centuries.

Natural dyestuff is mostly eco-friendly, biodegradable, less toxic and less allergic compared to synthetic dyes. Additionally, they are safe, and some have curative effects. ${ }^{3,4}$ Globally, the use of natural dyestuff for colouring textiles is majorly limited to small scale players involved in trading on this highly valued trade item. ${ }^{5}$ Natural dyeing is faced with many challenges viz; low substantively to fibre, requiring mordants, ${ }^{6}$ lengthy extraction, difficulty in blending, and lack of standard methods. ${ }^{7,8}$ The use of metallic mordants to form complexes has been a prominent feature in textile dyeing with natural dyes for a long time. This feature is because the mordants have been recognised to improve the colour characteristics of dyes of natural sources on fabrics. Alum $\left(\mathrm{KAl}\left(\mathrm{SO}_{4}\right)_{2} \cdot 12 \mathrm{H}_{2} \mathrm{O}\right)$, a metallic salt, is widely used as a mordant for dyeing various fibres with polyphenolic dyes to obtain bright colours and good fastness property, ${ }^{9}$ a process commonly referred to as mordanting.

Commonly, the traditional exhaust dyeing is laborious and excessively time-consuming, with others taking several days. The excessive demand for time in the dyeing processes stifle production and negates the advantages offered by natural dyes. This demand necessitates extensive scientific studies of dyeing kinetics to establish standard process variables. ${ }^{10}$ Various studies have been done to speed up dye uptake rate by fabrics through new technologies, namely, microwave, gamma and ultrasonicassisted processes. ${ }^{11,12,13}$ The new advances find a limited place in the natural dye industries, largely well-positioned in remote locations suited for more conventional and sustainable processes. The more conventional and sustainable processes further advocate for the need to extensively study exhaust dyeing kinetics to understand the mechanisms of chemical processes. Once these mechanisms are studied, appropriate means can be devised to speed the slow processes using bond enhancers (catalysts) or by modifying process variables. In this study, simultaneous and post-mordant dyeing methods with alum mordant using M. lucida plant extract for dyeing cotton and silk were studied.

In a recent study on the potential of indigenous plants for dyes in Uganda, many plant species were identified as sources of natural dyes for textile colouration, with M. lucida as one of them. ${ }^{14}$ This plant species is used as a strong herb in traditional therapy in Uganda. In addition, it imparts a fascinating yellow colour to textile fabrics. In a related study on colour characteristics imparted on cotton and silk fabrics, it has been reported that dye extracted from $M$. lucida registered excellent light and wash fastness with alum and ferrous sulphate mordants. ${ }^{15}$ Therefore, the plant finds another use as a natural dye source for the textile industry; however, further studies on its efficient extraction and application are necessary.

The study aimed to explore the dye-fibre adsorption isotherm, to understand the molecular distribution of dye to fibre. In addition, the study aimed at determining some kinetic parameters. Once these are determined, appropriate strategies can be sought and adopted to improve and speed up the chemical processes involved.

\section{Experimental}

2.1. Materials

The stem bark of the M. lucida plant was freshly picked 
from the Mukono District in Uganda. Scoured and bleached plain weave cotton fabric $(100 \%)$ was obtained from southern Range Nyanza Textile Mill, Jinja, Uganda. Degummed and bleached handloom weaved Bombyxomri Silk fabric (100\%) was obtained from Bushenyi Silk Farmers Association, Silk Mill in Shema District, Uganda. Alum powder AR grade from BDH and distilled water were used for making all solutions.

\subsection{Instruments}

Instruments used include; UV-Vis spectrophotometer Genesis 10S UV-Vis, a constant temperature water bath, an analytical balance, and a stop clock.

\subsection{Determination of time for complexation equilibrium}

In this study, alum mordant was used in the mordant exhaust dyeing of cotton and silk fabrics using simultaneous mordanting (SM) and post mordanting (PM) methods. At the preliminary stage of the study, the speed of dye-alum complex formation in solution was studied at $50{ }^{\circ} \mathrm{C}$. This study was necessary to determine equilibrium complexation time. An appropriate time is allowed during the study of dye-fibre adsorption to eliminate interfering parallel dye-mordant complexation reactions that may affect accurate observations.

Crude dye extract was obtained from the dried and pulverised stem bark of the M. lucida plant by standard aqueous method. ${ }^{16}$ The dried and pulverised plant sample (100 g) was soaked in distilled water $\left(500 \mathrm{~cm}^{3}\right)$ for $30 \mathrm{~min}$. The mixture was heated to boil and maintained at boiling temperature for $30 \mathrm{~min}$, after which it was allowed to cool. The reaction mixture was filtered to obtain a dye extract. A fraction of the extract $\left(350 \mathrm{~cm}^{3}\right)$ was diluted with distilled water to $1000 \mathrm{~cm}^{3}$ and kept as the dye liquor for subsequent experiments. The dye liquor was subjected to a qualitative UV scan to determine wavelength maxima ( $\lambda$ max), and its absorbance was also recorded at the $\lambda$ max. A fraction of dye liquor $\left(10 \mathrm{~cm}^{3}\right)$ was diluted with distilled water $\left(35 \mathrm{~cm}^{3}\right)$. To the diluted fraction $\left(45 \mathrm{~cm}^{3}\right)$ of dye liquor, an alum solution $\left(2.5 \mathrm{~g} / 1,5.0 \mathrm{~cm}^{3}\right)$ was added, stirred, and after 30 minutes, it was scanned qualitatively to note the shift in new absorbance maxima ( $\lambda$ max) due to complexation. To another fraction of dye liquor $\left(45 \mathrm{~cm}^{3}\right)$, alum solution $\left(2.5 \mathrm{~g} / 1,5.0 \mathrm{~cm}^{3}\right)$ was added, stirred, and a sample was immediately transferred into a UV cell. The change in absorbance was recorded at two minutes intervals at $50{ }^{\circ} \mathrm{C}$ in triplicates until no remarkable change in absorbance was recorded. This recording was done at the predetermined $\lambda$ max for the dye-alum solution.

\subsection{Determination of change in absorbance of solutions during various stages of dyeing}

\subsubsection{Simultaneous-mordant (SM) dyeing}

Two separate fractions of dye-bath solution $\left(200 \mathrm{~cm}^{3}\right.$, each) with $10 \%$ of alum on the weight of fabric (o.w.f) were preheated on a constant temperature water bath to $50{ }^{\circ} \mathrm{C}$. Cotton and silk fabrics ( $5 \mathrm{~g}$ each) were dipped in separate fractions. Each mixture was gently stirred continuously to maintain a homogenous condition in the dyebath. The material to liquor (M:L) ratio and mordant concentration (o.w.f) were maintained at 1:40 and $10 \%$ throughout the dyeing process. After 15 minutes, the absorbance of dye-bath liquor was determined in triplicate, and this was repeated every 15 minutes until no remarkable change in absorbance was recorded.

\subsubsection{Post-mordant (PM) dyeing}

This way of dyeing fabrics involves two processes done separately: applying the dye on fabric and mordanting the dye impregnated fabrics.

\section{Dyeing of fabrics without mordant}

Pieces of scoured degummed and bleached plain woven cotton and silk fabrics (5.0 g, each) were soaked in a suitable amount of distilled water $\left(300 \mathrm{~cm}^{3}\right)$ for 15 minutes before dyeing. Two fractions of dye liquor $\left(200 \mathrm{~cm}^{3}\right)$ were transferred into separate glass beakers $\left(500 \mathrm{~cm}^{3}\right)$. The fractions were preheated on a constant water bath to a temperature of $50{ }^{\circ} \mathrm{C}$, and the fabrics were separately transferred to the dye solutions (dyebaths). Dyeing was done at that temperature with an M:L ratio of 1:40. During dyeing, agitation was achieved by continuous stirring. After 15 minutes, liquor fractions were sampled and scanned for absorbance. These scans were done in triplicates every 15 minutes until no change in absorbance of the dye-bath liquor was recorded. The dyed fabrics were removed from the dyebath and allowed to dry for 30 minutes in the open air. After that, they were rinsed in tap water until there was no bleeding of colour. This rinsing was done to remove all the excess unbonded dye compounds.

\section{Mordanting the dye impregnated fabrics}

The absorbance of the alum solution $(1.0 \mathrm{~g} / \mathrm{l})$ was determined at the predetermined $\lambda$ max of $410 \mathrm{~nm}$. Fractions of mordant solutions $\left(200 \mathrm{~cm}^{3}\right)$ were transferred to two separate beakers and preheated over a constant temperature water bath to $50^{\circ} \mathrm{C}$. The previously dyed cotton and silk fabrics were separately transferred to the solutions. Mordanting was done with M:L ratios of 1:40, and the concentrations of mordant o.w.f were maintained at $4.0 \%$. During mordanting, there was a continuous stirring of the fabric mordant solution mixture. After 15 minutes, the mordant solution was sampled, and a UV scan conducted to determine absorbance. These scans were done in triplicates after every 15 minutes until no change in absorbance was recorded.

\subsection{Theoretical Approach}

Throughout the study, the changes in optical densities of dye solutions in terms of UV absorbance were used in place of molar concentrations. This approach is possible because dye solutions are strongly UV-Vis sensitive, and their optical densities in terms of absorbance are a direct function of their molar concentrations. It should then be noted that the concentration terms used here are absorbance, which is a relative value, i.e. unit less. The integrated rate equations for first- and secondorder kinetic models were used to evaluate the kinetic data. Additionally, selected models of adsorption isotherms were also used viz: Langmuir, Freundlich and Tempkin isotherms.

\subsubsection{The dyeing kinetic}

At the first stage, the integrated rate laws were applied to data obtained to predict the order of reactions. Then, the integrated rate laws for first- and second-order reactions were used with graphs to predict the reaction orders. As a result, the integrated rate laws for first- and second-orders are linearly expressed by equations 1 and 2 , respectively. ${ }^{17}$

$$
\begin{aligned}
& \ln [\mathrm{A}]=-\mathrm{kt}+\ln [\mathrm{A}]_{\mathrm{O}} \\
& \frac{1}{[\mathrm{~A}]}=\frac{1}{[\mathrm{~A}]_{0}}+\mathrm{kt}
\end{aligned}
$$

Plots resulting in linear relationships predict the reaction orders and determine the rate constants from the resulting slopes.

\section{Adsorption isotherms}

A study of the molecular distributions of the adsorbate (dye) and the adsorbent (fibre) was done. This study was done to understand the nature of the molecular distribution for the process at equilibrium. The amount of dye adsorbed is evaluated by a mass balance expressed in equation $3 .{ }^{18}$

$$
\mathrm{q}_{\mathrm{e}}=\mathrm{V}\left(\mathrm{C}_{\mathrm{i}}-\mathrm{C}_{\mathrm{e}}\right) / \mathrm{M}
$$

where $V$ is the volume of dye-bath solution, $C_{i}$ and $C_{e}$ are the initial and equilibrium concentrations (absorbance). The 
chemisorption study was conducted on Langmuir, Freundlich and Tempkin isotherms. The most suitable isotherm was compared by the values of regression coefficients $\left(r^{2}\right)$ and other constants. This approach is pertinent in the design of an adsorption system for the dyeing process. Langmuir isotherm theorises that sorption occurs at specific homogeneous sites within the adsorbent and assumes no further adsorption can occur at that site once a dye molecule occupies a given site. Therefore when equilibrium exhaustion is attained, no more sorption occurs. The Langmuir isotherm is linearly expressed in equation $4,{ }^{19}$

$$
\frac{\mathrm{C}_{\mathrm{e}}}{\mathrm{q}_{\mathrm{e}}}=\frac{1}{\mathrm{Q}_{0} \mathrm{~b}}+\frac{\mathrm{C}_{\mathrm{e}}}{\mathrm{Q}_{0}}
$$

For this study, the isotherm equilibrium constants are defines as follows: $C_{e}$ is equilibrium dye absorbance, $q_{e}$ is the quantity of dye adsorbed at equilibrium (absorbance/g), $Q_{0}$ is the limiting adsorption capacity when the fibre surface is fully exhausted with dye, it is useful in the comparison of adsorption performance of fibres, and $b$ is a constant related to the capacity of active binding sites. The value $q_{e}$ and $C_{e}$ were evaluated instantaneously at $C_{i}\left(C_{e}=C_{o}-C_{i}\right)$, where $C_{o}$ is initial absorbance.

Freundlich isotherm postulates non-homogenous surface energy distribution. Accordingly, the energy components in Langmuir vary proportionately to surface cover. The conventional logarithmic form of the Freundlich isotherm model is expressed in equation 5,20

$$
\log \mathrm{q}_{\mathrm{e}}=\log \mathrm{k}_{\mathrm{f}}+\frac{\log \mathrm{C}_{\mathrm{e}}}{\mathrm{n}}
$$

where $\mathrm{k}_{\mathrm{f}}$ and $1 / \mathrm{n}$ are Freundlich constant related to the capacity and intensity of adsorption, respectively. $\mathrm{k}_{\mathrm{f}}$ increases with the adsorption capacity of the adsorbent. $1 / n$ is the heterogeneity factor.

In the Tempkin and Pyzhev isotherm, consideration is made on the interactive effect of adsorbate-adsorbent. It postulates that the heat of molecular adsorption on the adsorbent surface decreases linearly. The isotherm is expressed in linear form in equation 6:

$$
\mathrm{q}_{\mathrm{e}}=\mathrm{B} \ln \mathrm{A}+\mathrm{B} \ln \mathrm{C}_{\mathrm{e}}
$$

where $\mathrm{B}$ and $\mathrm{A}$ are the isotherm constants evaluated from the plot of $\mathrm{q}_{\mathrm{e}}$ versus $\ln \mathrm{C}_{\mathrm{e}}$. $\mathrm{B}$ is closely related to the heat of adsorption, and $\mathrm{A}$ is the binding constant at equilibrium. ${ }^{21}$

\section{Results and discussions}

\subsection{The equilibrium complexation time}

The dye-mordant complexation resulted in a shift in the $\lambda$ max from $310 \mathrm{~nm}$ to $350 \mathrm{~nm}$ without mordant and with mordant, as shown in Figure 1 (a) and (b), respectively. The large bathochromic shift with complexation is due to the coordination of the lone pair electrons on the $\mathrm{O}$ donor atoms to the aluminium ion site. This electron coordination improves the hybrid configuration relative to the ground state, resulting in the observed longer wavelength absorption maxima. ${ }^{22}$

It is important to note that the absorption band around the new wavelength is increased, forming a peak with a gentle curve. The change in optical density in terms of absorbance with time during the dye-mordant complexation is included in Table 1. A plot of time versus absorbance (Figure 2) shows sufficient complexation of dye and alum at $50{ }^{\circ} \mathrm{C}$ as 10 minutes. This time is the equilibrium complexation time required for the dye compounds to complex sufficiently with the alum mordant. This time allows the dye-mordant complex to sufficiently equilibrate before putting the fabrics in the dye bath. So that dye-fibre complexation occurs in the absence of other parallel competing reactions. It is important for the kinetic study of dyefibre adsorption.
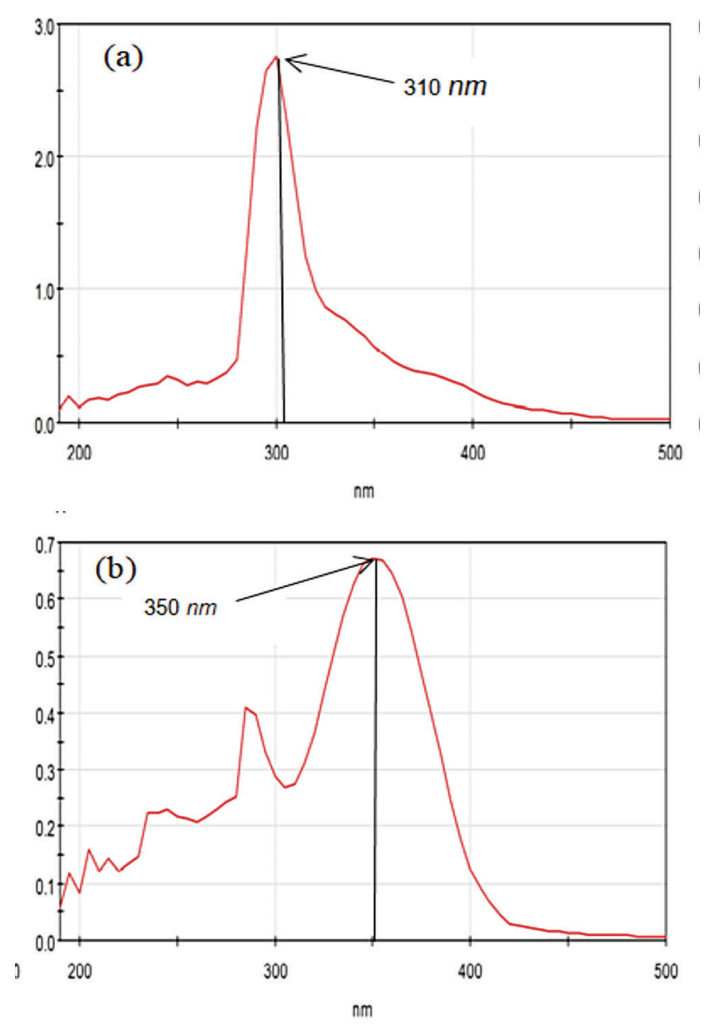

Figure 1 (a) UV-Vis spectrum of crude dye liquor of M. lucida, (b) UV-Vis spectrum of dye-mordant complex

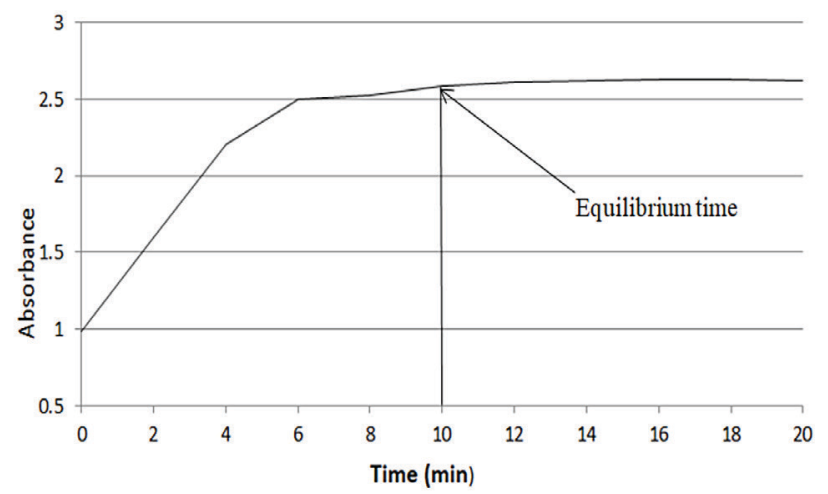

Figure 2 The trend of UV absorbance with time during dye-mordant complexation

Table 1 Change in absorbance during dye-mordant complexation at $50{ }^{\circ} \mathrm{C}$

\begin{tabular}{lccc}
\hline Time $/$ min & Absorbance at $350 \mathrm{~nm}$ & SD & \% error \\
\hline 0 & 0.983 & 0.0021 & 3.56 \\
2 & 1.598 & 0.0006 & 2.57 \\
4 & 2.207 & 0.0031 & 1.77 \\
6 & 2.496 & 0.0380 & 2.08 \\
8 & 2.525 & 0.0047 & 2.02 \\
10 & 2.588 & 0.0030 & 2.20 \\
12 & 2.608 & 0.0980 & 2.30 \\
14 & 2.607 & 0.0283 & 2.25 \\
\hline
\end{tabular}

SD: Standard deviation, $\%$ error: percentage error

\subsection{The adsorption kinetics}

The chemical processes involved in the dyeing of fabrics were treated differently per mordanting methods. From the data displayed in Table 2, remarkable changes in UV-absorbance 
Table 2 The change in UV absorbance of dye liquor during SM at $50{ }^{\circ} \mathrm{C}$

\begin{tabular}{lccccccc}
\hline \multirow{2}{*}{$\begin{array}{l}\text { Time } \\
(\text { min })\end{array}$} & \multicolumn{3}{c}{ Cotton } & & & \multicolumn{3}{c}{ Silk } \\
\hline 0 & Absorb. & SD & \% error & & Absorb. & SD & \% error \\
\hline 15 & 2.988 & 0.003 & 1.87 & & 2.988 & 0.026 & 2.01 \\
30 & 2.085 & 0.005 & 4.20 & & 2.706 & 0.096 & 2.44 \\
45 & 1.858 & 0.032 & 4.18 & & 2.503 & 0.052 & 2.95 \\
60 & 1.906 & 0.006 & 2.26 & & 2.288 & 0.003 & 4.33 \\
75 & 1.872 & 0.010 & 1.53 & & 1.980 & 0.032 & 3.83 \\
90 & 1.801 & 0.098 & 2.61 & & 1.699 & 0.001 & 5.77 \\
105 & 1.799 & 0.079 & 3.68 & & 1.582 & 0.002 & 2.84 \\
120 & 1.781 & 0.006 & 5.00 & & 1.503 & 0.007 & 2.26 \\
135 & 1.781 & 0.006 & 3.31 & & 1.498 & 0.001 & 1.87 \\
150 & 1.788 & 0.005 & 2.52 & & 1.446 & 0.005 & 2.70 \\
165 & 1.766 & 0.005 & 1.87 & & 1.447 & 0.001 & 1.24 \\
\hline
\end{tabular}

SD: Standard deviation, \% error: percentage error

were recorded up to between 60 to 120 minutes under various treatments. For SM, a plot of $1 /[\mathrm{A}]$ versus time is linear with positive slopes for both fabrics. Since the fabric matrix was intentionally put in a large excess of the dye, the rate of change in absorbance depended largely on the change in concentration of only one reactant (the dye). Therefore pseudo-second-order (PSO) reaction for the dye is predicted with good accuracy. The PSO rate constants $(\mathrm{k})$ were $4.6 \times 10^{-3}$ and $2.6 \times 10^{-3} \mathrm{~min}^{-1}$ for cotton and silk, respectively. These figures suggest that the speed of adsorption of dye on cotton fibre is faster than silk. However, from the absorbance values of residual dyebath liquor in Table 2, silk fibre takes more dye than cotton.

In PM, two steps were involved: contacting fibre with dye liquor in the absence of mordant (un-mordant dyeing) and contacting the dye-impregnated fabric with mordant solution (mordanting).

The change in absorbance of dye liquor with time during dye-fabric contact for PM is also included in Table 3. A plot of $1 /$ A ] versus time is linear with positive slopes for both fabrics Figure 3.

As in the previous case, a large excess of the fibre matrix was used; hence its concentration during dyeing remained constant. According to the experimental design, a PSO module concerning the dye liquor is predicted. The evaluated values of the rate constants $\left(\mathrm{k}_{1}\right.$ and $\left.\mathrm{k}_{2}\right)$ are $1.9 \times 10^{-2}$ and $1.3 \times 10^{-2} \mathrm{~min}^{-1}$ for cotton and silk, respectively. From values of rate constants, it is shown that cotton fabrics take in the dye compounds faster than silk. However, silk fabrics take more dye to achieve exhaustion, as reflected by absorbance values of residual dye in the bath. In mordanting the dyed fabrics, the change in optical

Table 3 The change in UV absorbance of dye bath liquor during PM at $50^{\circ} \mathrm{C}$

\begin{tabular}{lccccccc}
\hline \multirow{2}{*}{$\begin{array}{l}\text { Time } \\
(\text { min })\end{array}$} & \multicolumn{3}{c}{ Cotton } & & & \multicolumn{3}{c}{ Silk } \\
\cline { 2 - 5 } \cline { 6 - 7 } & Absorb. & SD & \% error & & Absorb. & SD & \% error \\
\hline 0 & 1.808 & 0.005 & 3.97 & & 1.801 & 0.005 & 4.88 \\
15 & 1.385 & 0.008 & 6.43 & & 1.518 & 0.006 & 4.35 \\
30 & 0.995 & 0.056 & 9.24 & & 1.196 & 0.002 & 4.68 \\
45 & 0.758 & 0.008 & 9.76 & & 0.831 & 0.001 & 4.57 \\
60 & 0.699 & 0.033 & 7.92 & & 0.749 & 0.046 & 5.54 \\
75 & 0.689 & 0.006 & 9.06 & & 0.595 & 0.057 & 2.88 \\
90 & 0.690 & 0.008 & 7.10 & 0.590 & 0.060 & 3.18 \\
105 & 0.689 & 0.009 & 7.55 & & 0.589 & 0.060 & 3.19 \\
120 & 0.689 & 0.008 & 8.56 & & 0.592 & 0.058 & 5.91 \\
135 & 0.690 & 0.018 & 5.70 & & 0.588 & 0.072 & 4.18 \\
150 & 0.689 & 0.008 & 4.06 & 0.587 & 0.061 & 5.78 \\
165 & 0.679 & 0.004 & 5.13 & 0.588 & 0.055 & 5.37 \\
\hline
\end{tabular}

SD: Standard deviation, \% error: percentage error

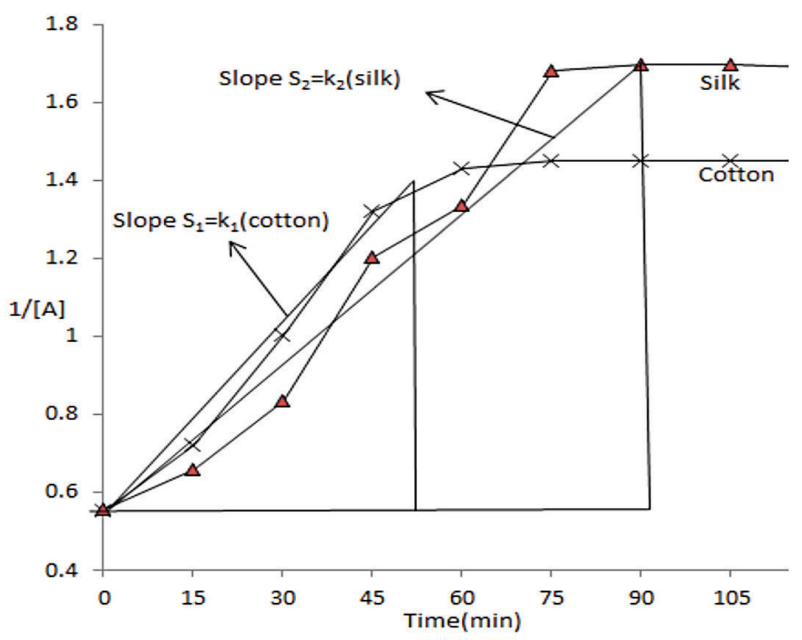

Figure $3 \mathrm{~A}$ plot of 1/[A] versus time (min) for cotton and silk PM dyeing

density of mordant solution with time is recorded in Table 4 . A plot of $\ln [\mathrm{A}]$ versus time produced a straight line with negative slopes for both cotton and silk fabrics (Figure 4). Therefore, a sufficiently dilute mordant solution was used, and the availability of the fibre matrix was maintained constant. Since the reaction behaviour is perfectly consistent with a system that obeys a first-order rate law, a pseudo-first-order (PFO) reaction module concerning the mordant is predicted. The values of rate constants $(\mathrm{k})$ were equal for both fabrics where $\mathrm{k}$ is $-3.9 \times 10^{-2} \mathrm{~min}^{-1}$. These values suggest that the fixation rates of mordant to fibre for the dye-impregnated fabrics are equal for both fabrics.

Fibre dyeing is a chemical process involving dye-fibre

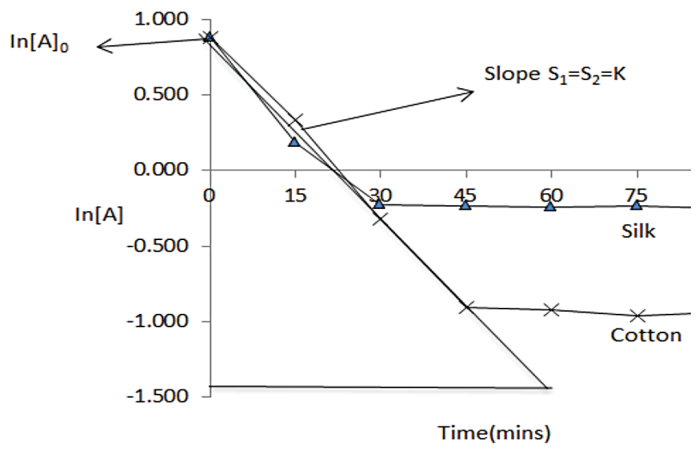

Figure 4 A plot of $\ln [\mathrm{A}]$ versus time (min) for mordanting dyed cotton and silk fabrics

Table 4 Change in absorbance of mordant solution during post mordanting at $50^{\circ} \mathrm{C}$

\begin{tabular}{lccccccc}
\hline \multirow{2}{*}{$\begin{array}{l}\text { Time } \\
(\mathrm{min})\end{array}$} & \multicolumn{3}{c}{ Cotton } & & & \multicolumn{3}{c}{ Silk } \\
\hline 0 & 2.401 & 0.001 & 3.00 & & 2.401 & 0.001 & 3.00 \\
15 & 1.403 & 0.006 & 4.20 & & 1.199 & 0.002 & 3.25 \\
30 & 0.725 & 0.003 & 5.38 & & 0.801 & 0.006 & 4.85 \\
45 & 0.405 & 0.005 & 4.94 & & 0.789 & 0.002 & 2.53 \\
60 & 0.399 & 0.002 & 5.51 & & 0.788 & 0.002 & 2.79 \\
75 & 0.382 & 0.002 & 4.97 & & 0.790 & 0.003 & 2.40 \\
90 & 0.391 & 0.004 & 5.89 & & 0.781 & 0.003 & 2.94 \\
105 & 0.389 & 0.006 & 5.61 & & 0.798 & 0.002 & 2.76 \\
120 & 0.388 & 0.001 & 5.92 & & 0.785 & 0.003 & 2.93 \\
135 & 0.389 & 0.001 & 4.90 & & 0.785 & 0.003 & 2.42 \\
\hline
\end{tabular}

SD: Standard deviation, \% error: percentage error 
complexation, an adsorption process involving an adsorbent and adsorbed system. In a study of natural dyeing of wool with extract of $A$. vasica, a pseudo-second-order mechanism with an activation energy of $69.039 \mathrm{kJmol}^{-1}$ was established, indicating chemisorption ${ }^{23}$, where the rate-controlling step is a chemical reaction. Furthermore, both the PM and SM of cotton and silk fabrics with dye extract of M. lucida follows a PSO model.

The change in activation energy largely influences the rate constants of second-order reactions independent of temperature change. Rates of such reactions are improved by an increase in reactants concentrations and bond enhancers. The dyeing process is generally slow, and their rates can be increased by raising the temperature of the dyebath solution. This rate increase is because raising the dyeing temperature helps open fibre structures, improving dyeability. ${ }^{24}$ The application of mordant onto dye-impregnated fabrics that follows a PFO model is characterised as physisorption, whose rates are favoured by an increase in the concentration of reactants and temperature.

A moderately high temperature is supported in practice since it increases kinetic energies and molecular movements, hence more dye-fibre contacts. However, it is also worth noting that high temperatures can destroy the fibre structures; therefore, moderate temperatures with bonding enhancers are recommended.

\subsection{The adsorption isotherms}

According to the Langmuir isotherm model, the plots of $1 / q_{e}$ versus $1 / c_{e}$ were linear for both $S M$ and PM in the case of cotton and silk fabrics (Figure 5). The correlations $\mathrm{r}^{2}$ of values 1.0 and 0.998 were also recorded. The values of Langmuir constants $\mathrm{Q}_{0}$ and $\mathrm{b}$, included in Table 5, were evaluated from the intercepts and slopes of the plots. However, they had little significance since a unit-less quantity absorbance was used in place of concentration. $\mathrm{R}_{\mathrm{L}}$ is an important characteristic of Langmuir isotherm, a dimensionless constant separation factor for equilibrium parameter. ${ }^{25,26}$ Its values were calculated and fell between 0.9307 and 1.0, signifying that the dyeing process is favourable and linear. Therefore, it is postulated that the dyeing processes follow the Langmuir model to form a monolayer at equilibrium.

Evaluation of experimental kinetic data for SM and PM, according to the Freundlich isotherm model, correlated in terms of $\mathrm{r}^{2}$ with values between 0.985 and 1.0 (Figure 6). This correlation also signifies that the dyeing adsorption follows the Freundlich isotherm model.

The constant $1 / \mathrm{n}$ (intensity factor) recorded for SM and PM were in the range of 7.0 to 10 and 1.0 to 9.0 for cotton and silk, respectively. Thus, the increase in the intensity factor in PM suggests more dye adsorption in the PM method on both fabrics.

Table 5 Values of isotherm constants for dyeing silk and cotton with M. lucida dye extracts at a temperature of $50^{\circ} \mathrm{C}$

\begin{tabular}{|c|c|c|c|c|c|}
\hline \multirow{2}{*}{$\begin{array}{l}\text { Isotherm } \\
\text { module }\end{array}$} & \multirow{2}{*}{$\begin{array}{l}\text { Evaluated } \\
\text { constants }\end{array}$} & \multicolumn{2}{|c|}{ Cotton fabric } & \multicolumn{2}{|c|}{ Silk fabric } \\
\hline & & SM & PM & SM & PM \\
\hline \multirow[t]{4}{*}{ Langmuir } & $\mathrm{Q}_{0} /\left(\mathrm{g}^{-1}\right) \times 10^{-2}$ & 1.99 & 0.75 & 1.25 & 1.5 \\
\hline & $\mathrm{b} \times 10^{-2}$ & 0.25 & 2.21 & 2.49 & 2.5 \\
\hline & RL & 1.00 & 0.949 & 0.931 & 0.943 \\
\hline & $\mathrm{r}^{2}$ & 1 & 1 & 1 & 0.998 \\
\hline \multirow[t]{3}{*}{ Freundlich } & $\mathrm{Kf} /\left(\mathrm{g}^{-1}\right)$ & 1.4 & 1.2 & 1 & 1.05 \\
\hline & $1 / \mathrm{n}$ & 7.1 & 10 & 1.0 & 9.09 \\
\hline & $\mathrm{r}^{2}$ & 1 & 1 & 1 & 0.985 \\
\hline \multirow{3}{*}{$\begin{array}{l}\text { Tempkin \& } \\
\text { Pyzhev }\end{array}$} & $\mathrm{B} /\left(\mathrm{g}^{-1}\right)$ & 11.5 & 28.3 & 36 & 26.6 \\
\hline & A & 1.667 & 1.711 & 2.207 & 1.462 \\
\hline & $\mathrm{r}^{2}$ & 0.978 & 0.919 & 0.958 & 0.951 \\
\hline
\end{tabular}
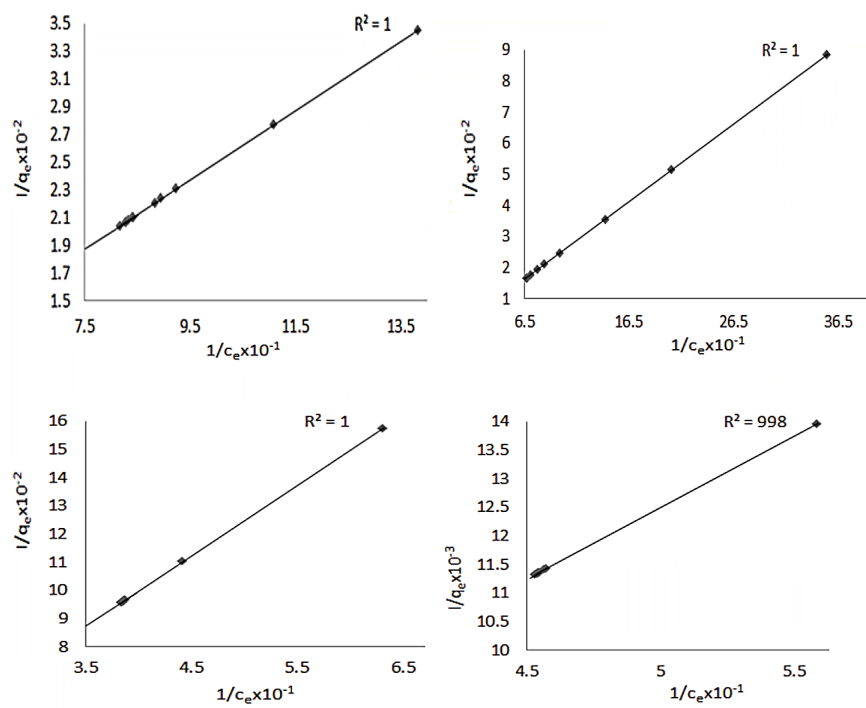

Figure 5 Plots for Langmuir isotherms at $50{ }^{\circ} \mathrm{C}$, (1): SM on cotton, (2): SM on silk, (3): PM cotton, (4): PM silk
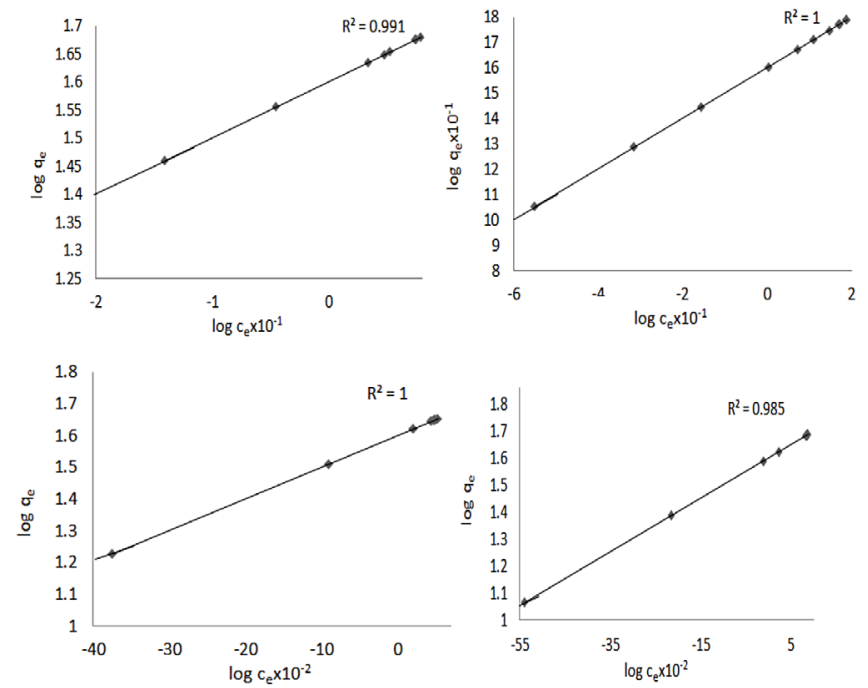

Figure 6 Plots for Freundlich isotherms at $50{ }^{\circ} \mathrm{C},(1)$ : SM on cotton, (2): SM on silk, (3): PM cotton, (4): PM silk
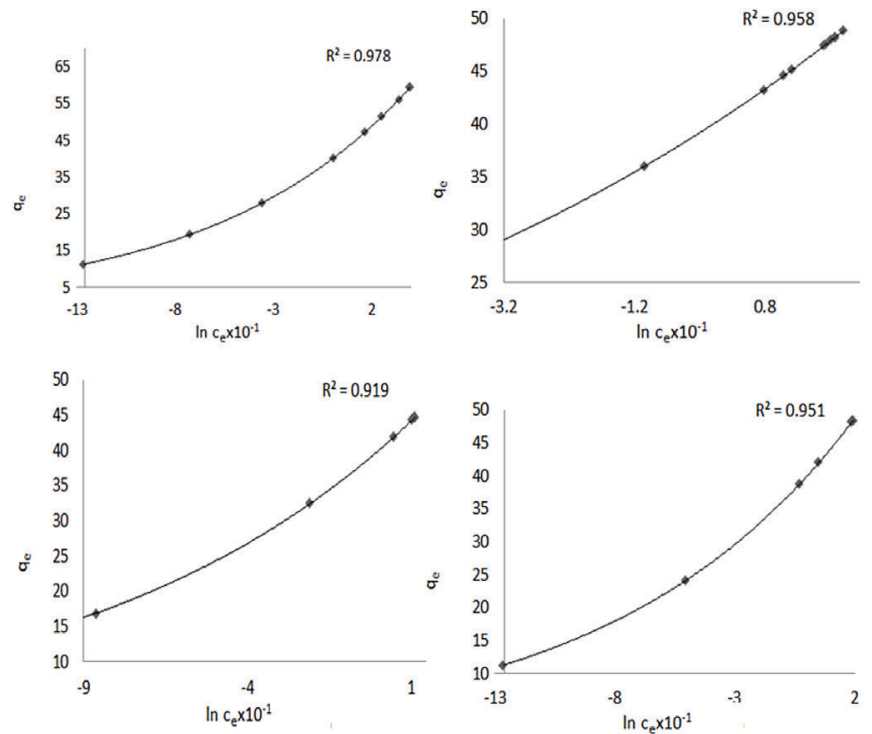

Figure 7 Plots for Tempkin \& Pyzhev isotherms at $50{ }^{\circ} \mathrm{C}$, (1): SM on cotton, (2): SM on silk, (3): PM cotton, (4): PM silk 
The application of experimental data on the Tempkin and Pyzhev isotherm model yielded curvilinear plots (Figure 7). The data correlation values of $\mathrm{r}^{2}$ lie between 0.919 and 0.979 . The constants A and B were evaluated from the intercepts and slopes of the respective graphs. From careful analysis, the characteristic plots disqualify the isotherm model in the present study.

More significant is the predicted formation of a monolayer on fibres, which calls for determining the optimum quantity of dye per unit mass of fabric that sufficiently forms complete surface coverage. The optimised dye quantity can significantly eliminate wastage and improves eco-safety. Additionally, according to the Freundlich model, the high intensity of dye on fibre in PM signifies that dye compounds effectively take up the active sites of fibre before introducing mordant. Simultaneous introduction of the mordant and the dye, as in SM, decreases dye intensity on the fibre surface. This decrease is largely due to competition between dye and mordant for active sites on fibre. Secondly, the dye-mordant complexes have large molecular configurations, therefore, reducing dye-fibre contacts. In this case, PM is strongly recommended for more intense shades of colour.

\section{Conclusion}

The experimental kinetic data in terms of UV absorbance for the dyeing of cotton and silk fabrics with dye from M. lucida is appropriate for predicting the orders of reactions and evaluation of adsorption isotherm models. PSO models were predicted for the post-mordanting and simultaneous mordanting at $50{ }^{\circ} \mathrm{C}$ for both fabrics. According to the experimental conditions, enhancing the speed of dye-fibre complexation to achieve equilibrium is favoured by using more concentrated dye solutions in dyebath. Mordanting of the dyed fabrics with alum $(4.0 \%$ o.w.f, $1.0 \mathrm{~g} / \mathrm{l})$ at $50^{\circ} \mathrm{C}$ follows a PFO module. Based on this fact, the process can be fastened by using mordant solutions of higher concentrations and increasing the process temperatures. Thus, the process of dyeing is adsorption that is closely consistent with Langmuir and Freundlich isotherm models.

Additionally, the dyeing is linear and favoured with the formation of a monolayer onto the fibre. More importantly, the Freundlich models revealed higher dye intensities on both fabrics in post mordant dyeing. Generally, silk adsorbs more dye than the cotton counterpart, but conversely, cotton has higher uptake of the alum mordant.

\section{Acknowledgement}

Recognition goes to Dr Justus Kwetegyeka and Asuman, the Dean faculty of science in Kyambogo University and Head of Chemistry lab at UIRI, respectively, to allow total access of their Chemistry laboratory for this study. In addition, Simon Peter, a laboratory technician at Kyambogo University, is also highly appreciated for his tremendous contribution in helping to run the UV-Vis spectrometer.

\section{ORCID iDs}

\section{Janani Loum: https://orcid.org/0000-0002-3951-141X}

\section{References}

1 R. Rajendarm, S. Mallick, NB. Das, B. Nanda, and S. Saiko, Dyeing and antimicrobial properties of cotton finished with Punica Granatum Extracts. J. Text. E Apparel Tech. \& Management, 2007, 7, 2.

2 E.S.B. Ferreira, A.N. Hulme, H. Macnab and A. Quve, Natural Constituents of historical Textile Dyes. Chem. Soc. Rev. 2004, 31, 329-336.

3 S. Han, and Y. Yang, Antimicrobial Activity of Wool Fabric Treated with Curcumin. Dyes and Pigments. 2005, 64, 157-161.
4 D.J. Hill, Is There a Future for Natural Dyes? Rev. Prog. Coloration, 1997, 27, 18-25.

5 T. Bechtold, R. Dan Mussack, Handbook of Colorant, Willey, 2009, 144 147.

6 D. Cordon, Dye plants. In: Natural Dye Sources Tradition, Technology and Sciences. $1^{\text {st }}$ ed., Archetype, London, 2007, 51-241.

7 M.D. Teli, R. Paul and P.D. Pardeshi, Natural Dyes: Classification, Chemistry and Extraction Methods. Colourage, 2000, 43-55.

8 R. Bhuyan, C.N. Saikia, and K.K. Das, Extraction and Identification of Color Components from the Bark of Mimusops Elengi and Terminalia Arjuna and Elevation of their Dyeing Characteristics on Wool. Ind. J. Fibre and Text. Res. 2004, 29, 470-476.

9 R.M. Christie, Colour Chemistry. Royal Soc. of Chem, U K. 2001, 12-44.

10 A.K. Samanta and A. Konar, Dyeing of Textiles with Natural Dyes. IntechOpen, 2011.

11 J. Sheikh, P.S. Jagtap and M.D. Teli, Ultrasound Assisted Extraction of Natural Dyes and Natural Mordants vis a vis Dyeing. Fibers Polym. 2016, 17, 738-743.

12 M.D. Teli, J. Sheikh and P.S.Jagtap, Microwave Assisted Extraction of Natural Dyes and Natural Mordants vis a vis Dyeing. Asian Dyer. 2013. DOI: $10.1007 / \mathrm{s} 12221016-5031$.

13 A.A. Khan, N. Iqbal, S. Adeel, M. Azeema, F. Batoolal, and L.A. Bhatti, Extraction of Natural Dye from Red calico Leaves: Gamma ray Assisted Improvements in Colour Strength and Fastness Properties. Dyes and Pigments. 2014, 103, 50-54.

14 P.A.G. Wanyama, B.T. Kiremire, P. Ogwok and J.S. Murumu, The Effect of Different Mordants on Strength and Stability of Color Produced from Selected Dye-Yielding Plants in Uganda, IAAST, 2010, 1, 81-92.

$15 \mathrm{~J}$. Loum. Dye for the future: natural dye from Morinda lucida plant for cotton and silk fabrics. Int J Res Rev. 2015; 2, 601-606.

16 H.T. Deo, and P. Roshan, Natural Dyeing of Denim with Eco-friendly Mordant. Text Bull., 2004, 5, 66-70.

17 R.H. Petrucci, General Chemistry: Principles and Modern Applications, $9^{\text {th }}$ Edn., New Jersey: Pearson Education Inc. 2007.

18 M. Alkan, M. Dogan, Y. Turhan, O. Demirbas and P. Turan, Adsorption kinetics and mechanism of maxilon blue $5 \mathrm{G}$ dye on sepiolite from aqueous solutions. Chem Engi. J., 2008, 139, 213-216.

19 I. Langmuir, The constitution and fundamental properties of solids and liquids. ACS., 1916, 38, 2221-2221.

20 H.M.F Freundlich, Over the Adsorption in Solution. J. Physics and Chemistry, 1906, 57, 385.

21 M. J. Tempkin and V. Pyzhev, Recent modifications to Langmuir isotherms. Acta Physiochim Undergraduate Research Scholarship Scheme, $1940,12,217-225$.

22 H. Zollinger, Color Chemistry. $3^{\text {rd }}$ ed. Verlag Helvetica Chimica Acta, Z rich, Wiley-VCH, Weinheim, 2003, 15-65.

23 L.J. Rather, S.U. Islam, M.A. Khan, F. Mohammad, Adsorption and Kinetic Study of Adhatoda vasica Dye onto Woollen Yarn with Evaluation of Colorimetric and Fluorescence Characteristics, J. Env. Chem. Eng, 2016, 4, 1780-1796.

24 S. Grishanov, Structure and Properties of Textile Materials. In: Handbook of Textile and Industrial Dyeing. De Montfort University, UK. Woodhead Publishing Limited. 2011, 43-54.

25 N. Kannan, and M. Sundaram, Kinetics and mechanism of removal of methylene blue by adsorption on various carbons-A comparative study. Dyes and Pigments, 2002, 51, 25-29.

26 A.K. Jain, V.K. Gupta and A.B. Suhas, Utilisation of industrial waste products as adsorbents for the removal of dyes. J. Hazardous Materials, 2003, 101, 31-35. 